\title{
Simple speed sensorless DTC-SVM scheme for induction motor drives
}

\author{
H. ABU-RUB ${ }^{1}$, D. STANDO ${ }^{2 *}$, and M.P. KAZMIERKOWSKI ${ }^{3}$ \\ ${ }^{1}$ Texas A\&M University at Qatar, Doha 23874, Qatar \\ ${ }^{2}$ Electrotechnical Institute, 28 Pożaryskiego St., 04-703 Warsaw, Poland \\ ${ }^{3}$ Institute of Control and Industrial Electronics, Warsaw University of Technology, 75 Koszykowa St., 00-662 Warsaw, Poland
}

\begin{abstract}
The paper focuses on the development of a novel DSP based high performance speed sensorless control scheme for PWM voltage source inverter fed induction motor drives. Firstly, two generic torque and flux control methods the Field Oriented Control (FOC) and Direct Torque Control (DTC), are briefly described. For implementation the sensorless scheme DTC with Space Vector Modulation (DTC$S V M$ ) has been selected because it eliminates the disadvantages associated with the DTC while keeping the advantages of both FOC and DTC. Secondly, the simple flux vector observer allowing speed sensor elimination is given. The novelty of the presented system lays in combining the DTC-SVM structure with a simple observer for both torque/flux and speed sensorless control. Furthermore, the DTC-SVM structure which operates in speed sensorless and torque control mode is presented. Finally, the description of a $50 \mathrm{~kW}$ laboratory drive and experimental results illustrating properties of the system are given.
\end{abstract}

Key words: speed sensorless control, pulse width modulated (PWM) voltage source inverters, induction motor drives, direct torque control (DTC), DTC-SVM, adjustable speed drives (ASD).

\section{Introduction}

The converter-fed adjustable speed drives (ASD) with induction motor (IM) are widely used in industry and transportation systems. In the last decade, several techniques are developed which allow for elimination of motion (speed or position) shaft sensor of IM drives while keeping enough precision and high dynamic performance. The techniques used for speed/position elimination are known in the literature as sensorless or encoderless [1-4]. Among the main advantages of sensorless controlled drives there are:

- Lower cost,

- Reduced hardware complexity,

- Reduced size of the drive,

- Elimination of the sensor cables,

- Higher noise immunity,

- Lower maintenance requirements,

- Possible operation in aggressive environments,

- Reliable, and user friendly operation.

The basic principles used for speed/position estimation (observation) can be classified into [1, 3, 4]: speed estimators, model reference adaptive system (MRAS), adaptive observers, Kalman filters, rotor slot ripple. All these methods, except rotor slot ripple, are based on flux vector observers for speed estimation.

In this work the development and investigation of the simple speed sensorless vector controlled IM drive which can operate in both torque or speed control modes is presented. In the first part, the paper discusses torque and flux control methods and for practical implementation the DTC with Space
Vector Modulation (DTC-SVM) has been chosen because it eliminates the traditional DTC disadvantages while keeping the advantages of both classical FOC and DTC schemes. Further, the simple flux vector observer allowing speed sensor elimination is presented. The novelty of the presented system consists in combining the universal DTC-SVM structure with a simple observer for both torque/flux and speed sensorless control. Finally, the description of the $50 \mathrm{~kW}$ laboratory drive system with DSP based control and estimation as well as experimental results illustrating properties of the developed system are given.

\section{Control schemes}

2.1. Complex space vector based equation of induction motor (IM). Mathematical description of the three-phase IM is based on complex space vectors, which are defined in the coordinate system rotating with the synchronous angular speed $\Omega_{s}$. In absolute-units and real-time representation the following equations describe a behaviour of the idealized cage-rotor IM [2-5]:

$$
\begin{gathered}
\mathbf{V}_{s}=R_{s} \mathbf{I}_{s}+\frac{d \boldsymbol{\Psi}_{s}}{d t}+j \Omega_{K} \boldsymbol{\Psi}_{s} \\
0=R_{r} \mathbf{I}_{r}+\frac{d \boldsymbol{\Psi}_{s}}{d t}+j\left(\Omega_{K}-p_{b} \Omega_{m}\right) \mathbf{\Psi}_{r} \\
\boldsymbol{\Psi}_{s}=L_{s} \mathbf{I}_{s}+L_{M} \mathbf{I}_{r} \\
\boldsymbol{\Psi}_{r}=L_{r} \mathbf{I}_{r}+L_{M} \mathbf{I}_{s} \\
\frac{d \Omega_{m}}{d t}=\frac{1}{J}\left(T_{e}-T_{L}\right) .
\end{gathered}
$$

*e-mail: d.stando@iel.waw.pl 
The electromagnetic torque $T_{e}$ can be expressed by the following formula:

$$
T_{e}=p_{b} \frac{3}{2} \operatorname{Im}\left(\Psi_{s} * \mathbf{I}_{s}\right),
$$

where $\mathbf{I}_{r}$ - rotor current space vector, $\mathbf{I}_{s}$ - stator current space vector, $J$ - moment of inertia, $L_{M}$ - main, magnetizing inductance, $L_{s}$ - stator winding self-inductance, $L_{r}$ - rotor winding self-inductance, $T_{e}$ - electromagnetic torque, $T_{L}-$ load torque, $p_{b}$ - number of pole pairs, $R_{r}$ - rotor phase windings resistance, $R_{s}$ - stator phase windings resistance, $\mathbf{V}_{s}$ - stator voltage space vector, $\boldsymbol{\Psi}_{\mathrm{S}}$ - vector of the stator flux linkage, $\Psi_{\mathbf{r}}-$ vector of the rotor flux linkage, $\Omega_{K}-$ angular speed of the coordinate system, $\Omega_{m}$ - angular speed of the IM shaft.

\subsection{General block scheme of speed controlled IM drive.}

The general block scheme of high performance speed controlled induction motor drive is shown in Fig. 1. The core of the scheme are inner flux and torque control loops with the estimator block which can be implemented in different ways, whereas the outer speed control loop is rather unified and generates command values for torque $T_{c}$ and flux $|\Psi|_{c}$ (via Flux program block) controllers. The speed feedback signal can be measured by a mechanical motion (speed/position) sensor $\Omega_{m}$ or calculated in the estimator $\widehat{\Omega}_{m}$ creating possibility of the motion sensorless operation.

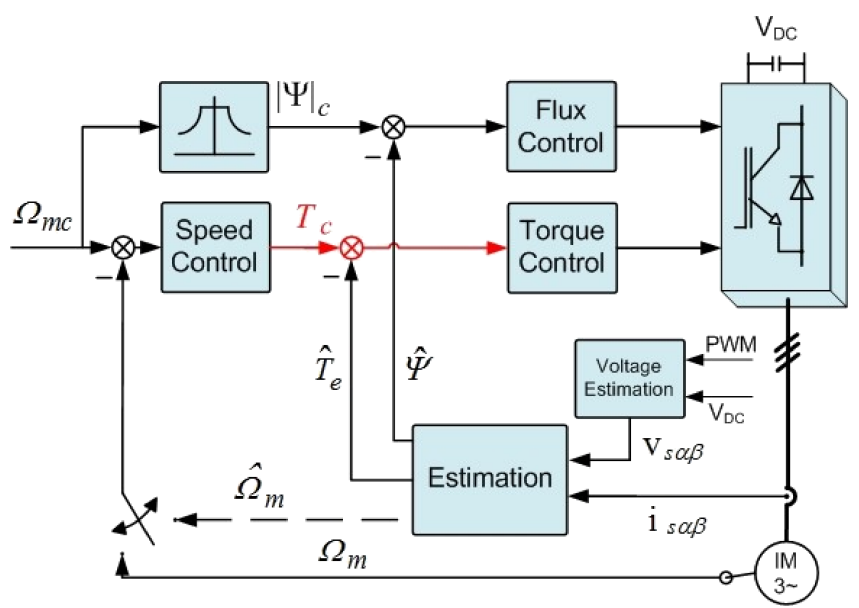

Fig. 1. General block scheme of speed controlled induction motor drive

2.3. Selection of torque and flux control methods. Several basic Torque Control (TC) methods have been developed in the last decades [7]. Not all of them have found wide industrial applications. Therefore, we present only most popular strategies used commercially.

Field Oriented Control (FOC). The proposed in 1970-ties by Hasse [8] and Blaschke [9] FOC method is based on an analogy to the DC brush motor. In this motor, owing to separate exciting and armature windings, flux is controlled by exciting current and torque is controlled independently by adjusting the armature current. So, the flux and torque currents are electrically and magnetically separated. Contrarily, the cage-rotor IM has only a three-phase winding in the stator, and the stator current vector, $\mathbf{I}_{s}$, is used for both flux and torque control. So, exciting and armature current are coupled (not separated) in the stator current vector and cannot be controlled separately. The decoupling can be achieved by the decomposition of the instantaneous stator current vector, $\mathbf{I}_{s}$, into two components: flux - producing current, $i_{s d}$, and torque-producing current, $i_{s q}$, in the rotor-flux-oriented coordinates (R-FOC) $d q$ (see vector diagram in Fig. 2). In this way, the control of the IM becomes identical with a separately excited DC brush motor and can be implemented using a current controlled PWM inverter with linear PI controllers and voltage SVM (see block scheme in Fig. 2). The core of the FOC scheme are coordinate transformation blocks which allow calculation of field oriented current components $i_{s d}, i_{s q}$ by using $\alpha \beta / \mathrm{dq}$ transformation, and reference voltage vector components $v_{s \alpha c}, v_{s \beta c}$ by using dq $/ \alpha \beta$ transformation. So, in the FOC scheme torque and flux are controlled indirectly by field oriented current vector components.

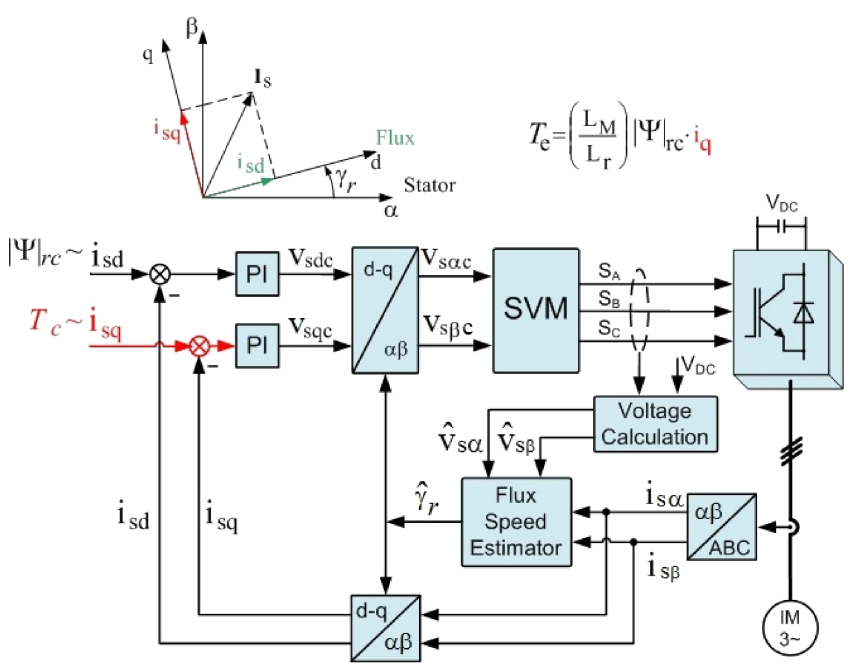

Fig. 2. Vector diagram and block scheme of rotor FOC. Torque and flux are controlled indirectly via torque current $i_{s q}$ and flux current $i_{\text {sd }}$ control loops

Switching Table based - DTC Scheme (ST-DTC). The block diagram of the ST-DTC scheme proposed by Takahashi and Noguchi [10] is shown in Fig. 3. The stator flux magnitude $|\boldsymbol{\Psi}|_{s c}$ and the motor torque $T_{c}$ are the command signals which are compared with the estimated $|\widehat{\Psi}|_{s}$ and $\widehat{T}_{e}$ values, respectively. The digitized flux and torque errors generated by the hysteresis controllers $d_{\Psi}, d_{T}$ and the position sector $N\left(\gamma_{s}\right)$ of the stator flux vector obtained from the angular position $\gamma_{s}=\operatorname{arctg}\left(\Psi_{s \beta} / \Psi_{s \alpha}\right)$ selects the appropriate voltage vector from the switching selection table. Thus, pulses $S_{A}$, $S_{B}, S_{C}$ for control the inverter power switches are generated from the vector selection table.

The characteristic features of the ST-DTC scheme of Fig. 3 include:

- Sinusoidal stator flux and current waveforms with harmonic content determined by the flux and torque controller hysteresis tolerance bands, 
- Excellent torque dynamics (depending on voltage reserve),

- Flux and torque hysteresis bands determine the inverter switching frequency, which varies with the synchronous speed and load changes.

Compared to the conventional FOC (Fig. 2), the DTC has the following features:

- Simple structure,

- There is no current control loops; hence, the current is not regulated directly;

- Coordinate transformation is not required,

- There is no separate voltage pulse width modulator (PWM),

- Accurate stator flux vector and torque estimation is required.

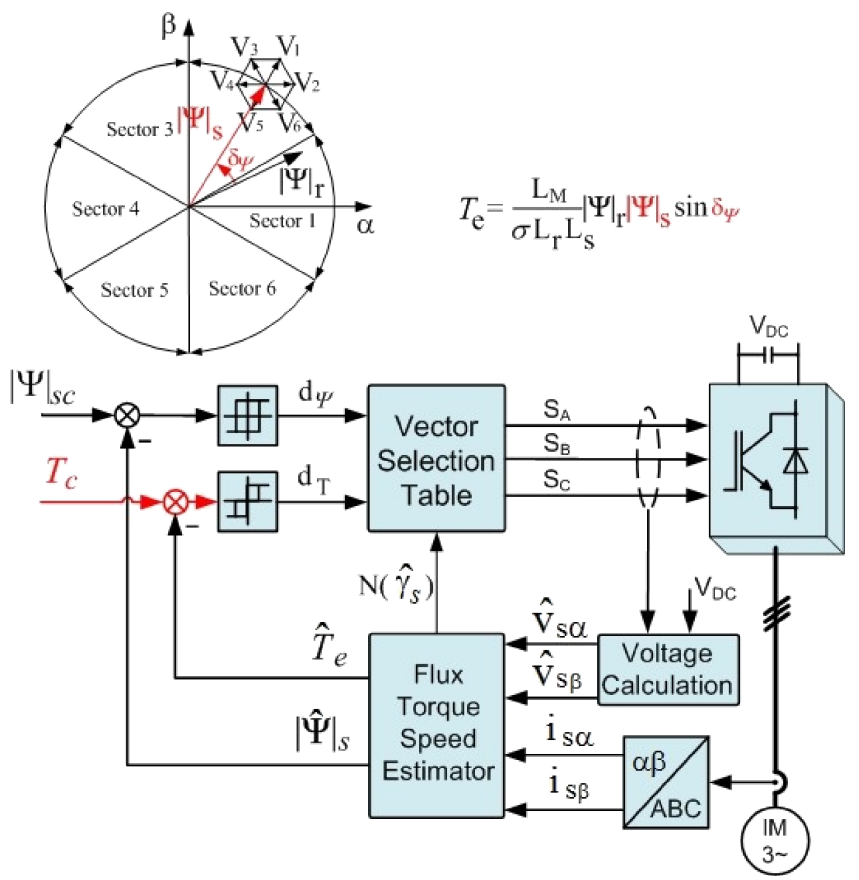

Fig. 3. Vector diagram and block scheme of Switching Table based DTC. Torque and flux are controlled directly by selection of appropriate forward/backward active inverter voltage vector $\left(V_{1}\right.$ or $\left.V_{6}\right)$ and stops by selection zero voltage vector $V_{0}$. Stator flux vector moves on circular path

Direct Torque Control with Space Vector Modulation (DTC-SVM). Many modifications of the classical ST-DTC scheme aimed at improving starting, very low speed operation, torque ripple reduction, overload conditions, variable switching frequency functioning, and noise level attenuation have been proposed during last decade [11]. One of the solutions is the DTC-SVM with closed-loop torque and flux control operating in Cartesian stator flux coordinates (Fig. 4)
$[1,6,11]$. The output of the PI flux and torque controllers is interpreted as the reference stator voltage component, $v_{\Psi c}$ and $v_{T c}$, in stator flux oriented (S-FOC) $(d q)$ coordinates. These DC voltage commands are then transformed into stationary coordinates $(\alpha \beta)$, and the commanded values, $v_{s \alpha c}$ and $v_{s \beta c}$, are delivered to the SVM block. Note that this scheme can be seen as simplified S-FOC without current control loops [12] or as classical ST-DTC scheme (see [10]) in which switching table is replaced by modulator (SVM) and hysteresis torque and flux controllers are replaced by linear PI [1, 6, 13]. So, in the DTC-SVM scheme torque and flux are controlled directly in closed loops, and therefore an accurate estimation of motor flux and torque is necessary. Differently from the nonlinear DTC scheme where signals are processed on instantaneous values, in the linear DTC-SVM scheme, the linear (PI) controllers operate on values averaged over the sampling period. Therefore, the sampling frequency can be reduced from about $40 \mathrm{kHz}$ required in nonlinear DTC, to $2-5 \mathrm{kHz}$ in linear DTCSVM scheme. Also, operation at constant switching frequency improves considerably the drive performance in terms of reduced torque and flux pulsations, reliable start-up and low speed operation.

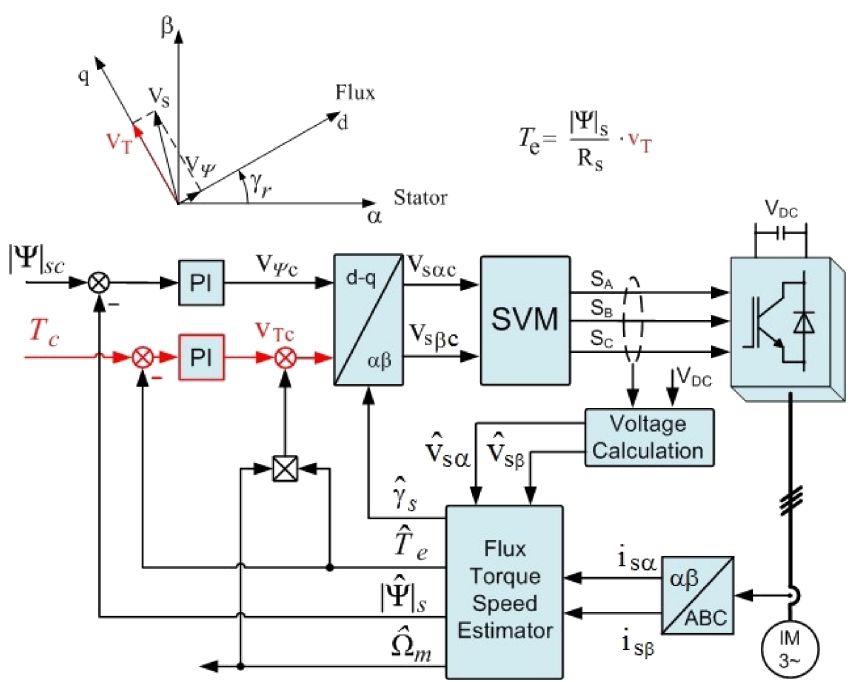

Fig. 4. Vector diagram and block scheme of the implemented DTCSVM. Torque and flux are controlled directly via stator voltage vector components $\mathrm{v}_{M c}$ and $\mathrm{v}_{\Psi_{c}}$

Table 1 summarizes features of described torque and flux control methods. It can be seen that DTC-SVM is a combination of DTC and FOC which eliminates basic disadvantages while keeping main advantages of both methods. Therefore, the DTC-SVM scheme has been selected for implementation of speed sensorless IM drive. 
Table 1

Comparison of control methods

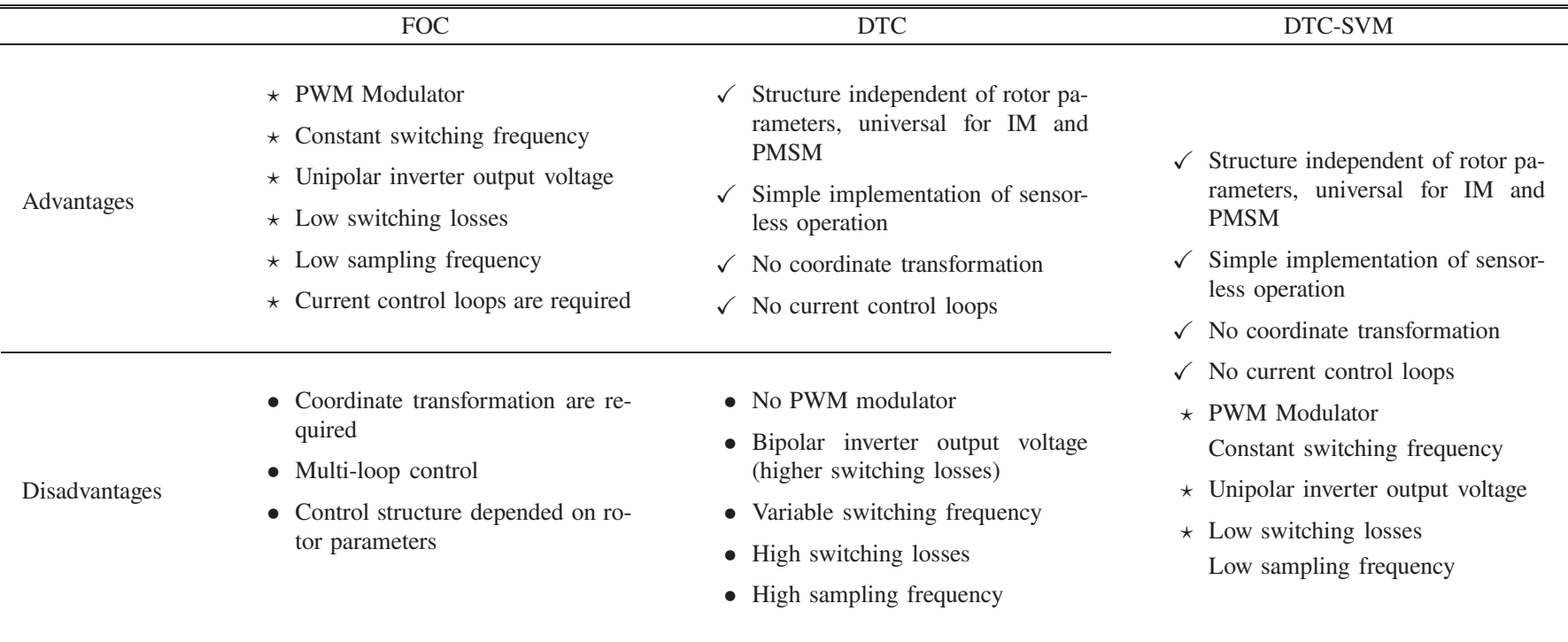

\section{Flux vector and angular speed estimation}

Implementation of any high performance drive system requires a high accuracy estimation of the actual stator or/and rotor flux vector (magnitude and position) and electromagnetic torque. Once the flux vector is accurately estimated, the torque estimation is performed easily as a cross product of the flux and measured stator current vectors. Also, there is a strong trend to avoid AC voltage sensors and mechanical motion (speed/position) sensors because it reduces cost and improves reliability and functionality of the drive system. A good review of IM speed sensorless control schemes is presented in $[4,12,14]$.

3.1. Flux Vector Estimation. To avoid the use of flux sensors or measuring coils in the IM, methods of indirect flux vector generation have been developed, known as flux models or flux estimators. These are models of IM equations which are excited by appropriate easily measurable quantities, such as stator voltages and/or currents $\left(\mathbf{V}_{s}, \mathbf{I}_{s}\right)$, angular shaft speed $\left(\Omega_{m}\right)$ or position angle $\left(\gamma_{m}\right)$. There are many types of flux vector models, which usually are classified in terms of the input signals used [3-5]. Such models generate the stator or/and rotor flux vector which, in an ideal case, rotates synchronously with the IM magnetic field. Because the IM parameters very often are known only roughly, and change with operating point and temperature, therefore an error appears between the actual IM flux and that estimated in the used model. The error depends on: model variants, parameter deviation between IM and model, accuracy of input signal measurement, motor point of operation. To minimize the sensitivity of flux models to motor parameters variation, use is made of the model adaptive reference systems (MARS) and the observer technique $[15,16]$. Also, sliding mode approach for robust flux estimation has been proposed [17].
In this work a simple stator flux vector observer operating without speed/position signal has been implemented. The observer equations (7)-(10) are derived from the IM space vector Eqs. (1)-(4), and are expressed as [18, 19]:

$$
\begin{gathered}
\frac{d \widehat{\mathbf{\Psi}}_{s}^{I}}{d t}=\left(-\widehat{\boldsymbol{\Psi}}_{s}^{I}+\frac{L_{M}}{L_{r}} \widehat{\mathbf{\Psi}}_{r}\right) \frac{R_{s}}{\sigma L_{s}}+\mathbf{V}_{s}-K\left(\mathbf{I}_{s}-\widehat{\mathbf{I}}_{s}\right) \\
\frac{d \widehat{\mathbf{\Psi}}_{s}^{I I}}{d t}=\mathbf{V}_{s}-R_{s} \mathbf{I}_{s} \\
\widehat{\mathbf{\Psi}}_{r}=\left(\widehat{\mathbf{\Psi}}_{s}^{I I}-\sigma L_{s} \mathbf{I}_{s}\right) \frac{L_{r}}{L_{M}} \\
\widehat{\mathbf{I}}_{s}=\left(\widehat{\Psi}_{s}^{I}-\frac{L_{M}}{L_{r}} \widehat{\mathbf{\Psi}}_{r}\right) / \sigma L_{s}
\end{gathered}
$$

The correction term $K\left(\mathbf{I}_{s}-\mathbf{I}_{s}\right)$ existing in the observer equation (7) is calculated as an error between the currents: measured $\mathbf{I}_{s}$ and estimated $\widehat{\mathbf{I}}_{s}$ in equation (10). This error term is multiplied by gain factor $K$ allowing compensation of a drift and parameter changes. This $K$ factor was tuned according to a discussion conducted in [19]. The rotor flux vector is calculated using the equation (9).

3.2. Speed estimation. Estimated rotor flux vector $\Psi_{r}$ and measured stator currents, allow to calculate the IM mechanical angular speed as:

$$
\widehat{\Omega}_{r}=\widehat{\Omega}_{s}-\frac{L_{M}}{T_{r}} \frac{\widehat{\Psi}_{r \alpha} i_{s \beta}-\widehat{\Psi}_{r \beta} i_{s \alpha}}{\left|\widehat{\Psi}_{r}\right|^{2}},
$$

where $T_{r}$ - rotor time constant, $i_{s \alpha}$ and $i_{s \beta}$ - current vector components in the stationary $\alpha-\beta$ coordinates.

The block diagram of the implemented stator flux vector and angular speed estimation according to Eqs. (7)-(10) and (11) is shown in Fig. 5. 
Simple speed sensorless DTC-SVM scheme for induction motor drives

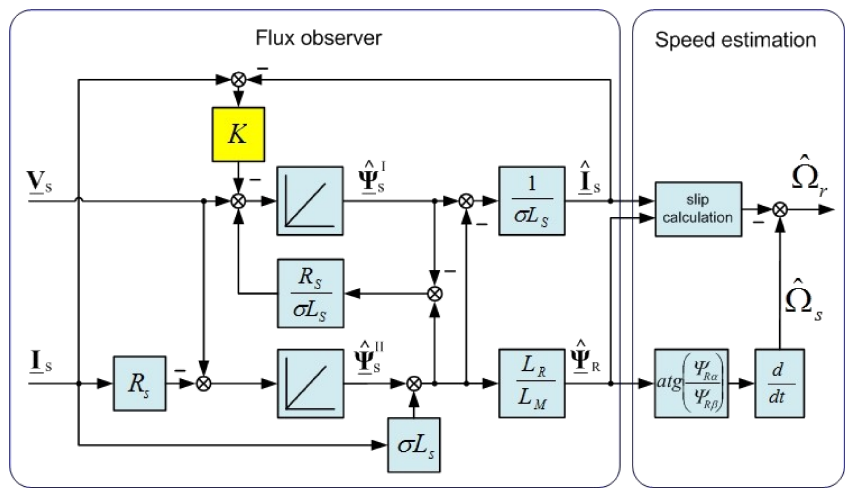

Fig. 5. Block diagram of flux observer and speed calculation structure

\section{Description of the laboratory drive system}

The laboratory setup consists of two identical $50 \mathrm{~kW}$ induction motors each supplied by back-to-back AC-DC-AC voltage source power converters (Fig. 6). So, the converter system allows for motor and generator mode of operation. The parameter specification of the IM and converters are given in Table 2.

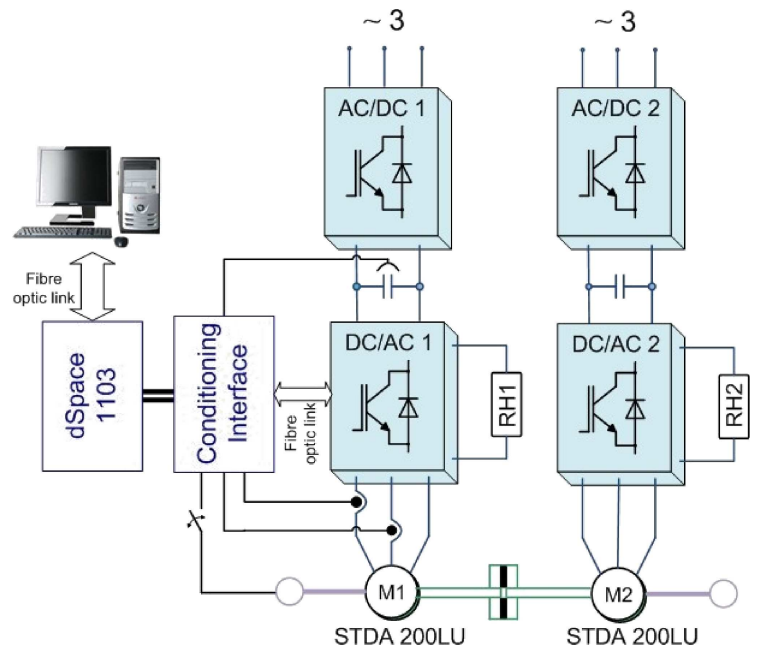

Fig. 6. Block scheme of laboratory setup

Table 2

Laboratory setup specification

\begin{tabular}{cccc}
\hline \multicolumn{4}{c}{ IM type STDA 200LU } \\
\hline$P_{N}$ & $50 \mathrm{~kW}$ & $R_{s}$ & $64.5 \mathrm{~m} \Omega$ \\
\hline$V_{N}$ & $3 \times 380$ & $R_{r}$ & $46.3 \mathrm{~m} \Omega$ \\
\hline$I_{N}$ & $88 \mathrm{~A}$ & $L_{s}$ & $25.217 \mathrm{mH}$ \\
\hline$f_{N}$ & $65 \mathrm{~Hz}$ & $L_{r}$ & $25.137 \mathrm{mH}$ \\
\hline$T_{e N}$ & $249 \mathrm{Nm}$ & $L_{M}$ & $24.75 \mathrm{mH}$ \\
\hline$\Omega_{N}$ & $1917 \mathrm{rpm}$ & $\mathrm{J}$ & $10 \mathrm{~kg} \cdot \mathrm{m}^{2}$ \\
\hline \multicolumn{3}{c}{ Power converter } & $\mathrm{AC} / \mathrm{DC}$ and DC/AC \\
\hline \multicolumn{3}{c}{$P_{N}$} & $55 \mathrm{~kW}$ \\
\hline$I_{N}$ & $98 \mathrm{~A}$ \\
\hline$V_{N}$ & $3 \times 400 \mathrm{~V} 50 \mathrm{~Hz}$ \\
\hline$f_{i m p}$ & $4 \mathrm{kHz}$ \\
\hline
\end{tabular}

The proposed DTC-SVM scheme was implemented in a dSpace 1103 platform and some auxiliary circuits were used.
The conditioning interface includes: conditioning current signal from LEM sensors to voltage in appropriate range for dSpace card, over current and over voltage protection, and also fibre optics link for IGBT power transistors.

\section{Real-time implementation of control and estimation algorithms}

The whole control and estimation algorithm have been implemented in C language using ControlDesk software provided by dSpace [20, 21]. The algorithm structure is shown in Fig. 7. The main parts are: estimation and DTC-SVM block. The estimation block contains Eqs. (7)-(11) and Fourth-Order Runge-Kuta Method (RK4). The RK4 integration method requires large amount of calculations, more than e.g. the Euler method, but it is more precise, giving higher stability of the estimator. The DTC-SVM block contains a control structure consisting of linear PI regulators and a space vector modulator.

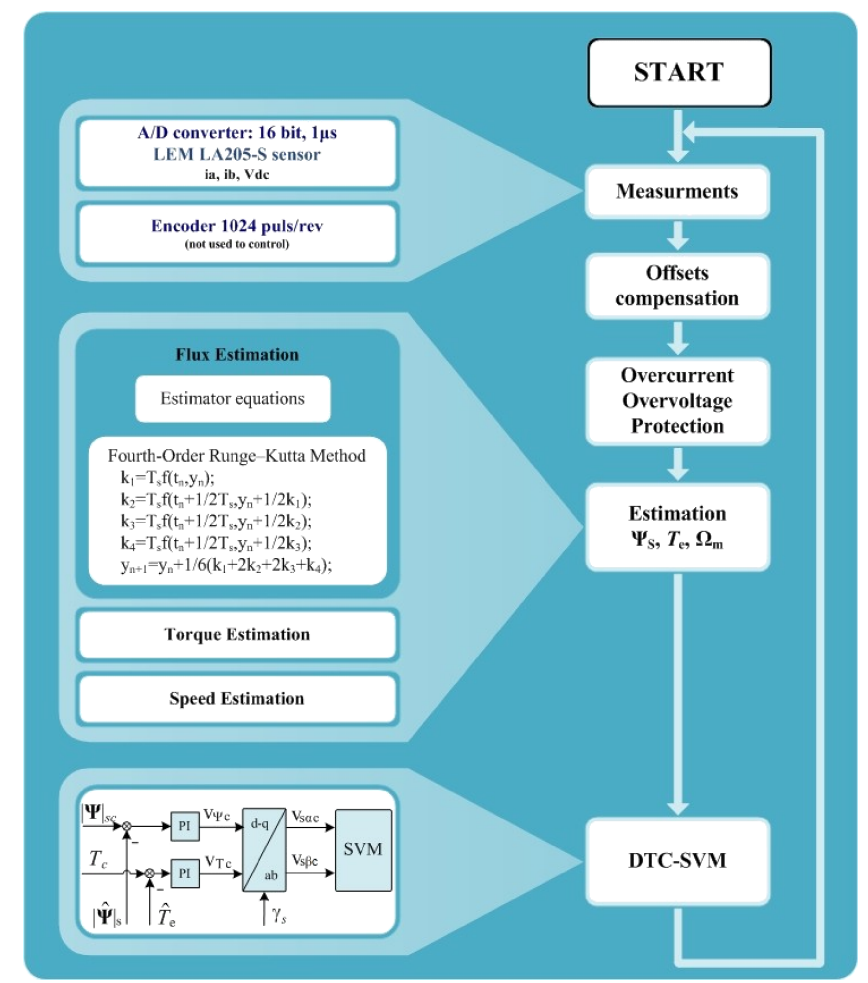

Fig. 7. Block scheme of the implemented estimation and DTC-SVM algorithm

The control action of the whole system is synchronized with the SVM-generation and executed with sampling time $250 \mu$ s equal to the inverter switching time.

\section{Experimental results}

The presented algorithm has been investigated experimentally in steady states and dynamic operation for different IM speeds and loads.

Steady state performances. At first, the accuracy of the speed estimation in region of the reference speeds $10-1100 \mathrm{rpm}$, and 
H. Abu-Rub, D. Stando, and M.P. Kazmierkowski

load torque of $100 \mathrm{Nm}$ and $200 \mathrm{Nm}$ have been investigated and results are summarized in Table 3 . As it can be seen, the speed error is within the range of 2.6-3.76 rpm and for the load torque $200 \mathrm{Nm}$ is approximately two times higher than for $100 \mathrm{Nm}$.

Table 3

Speed estimation errors for different speed and load torque values

\begin{tabular}{ccc}
\hline & \multicolumn{2}{c}{$T_{\text {load }}$} \\
\cline { 2 - 3 }$\Omega$ & $100 \mathrm{Nm}$ & $200 \mathrm{Nm}$ \\
\hline$\Omega \mathrm{m}[\mathrm{rpm}]$ & $\Delta \Omega \mathrm{m}[\mathrm{rpm}]$ & $\Delta \Omega \mathrm{m}[\mathrm{rpm}]$ \\
\hline 1100 & 3.76 & 7.7 \\
\hline 700 & 3.6 & 7.4 \\
\hline 300 & 3.6 & 7.2 \\
\hline 100 & 3.4 & 6.8 \\
\hline 50 & 3.3 & 5.7 \\
\hline 40 & 3 & 5.7 \\
\hline 30 & 2.6 & 5.4 \\
\hline 15 & 2.7 & 5.5 \\
\hline 10 & 2.7 & 5.3
\end{tabular}

Secondly, the operation of the IM speed sensorless drive in steady state at speed $1100 \mathrm{rpm}$ and load torque $200 \mathrm{Nm}$ has been illustrated in oscillograms of Fig. 8.

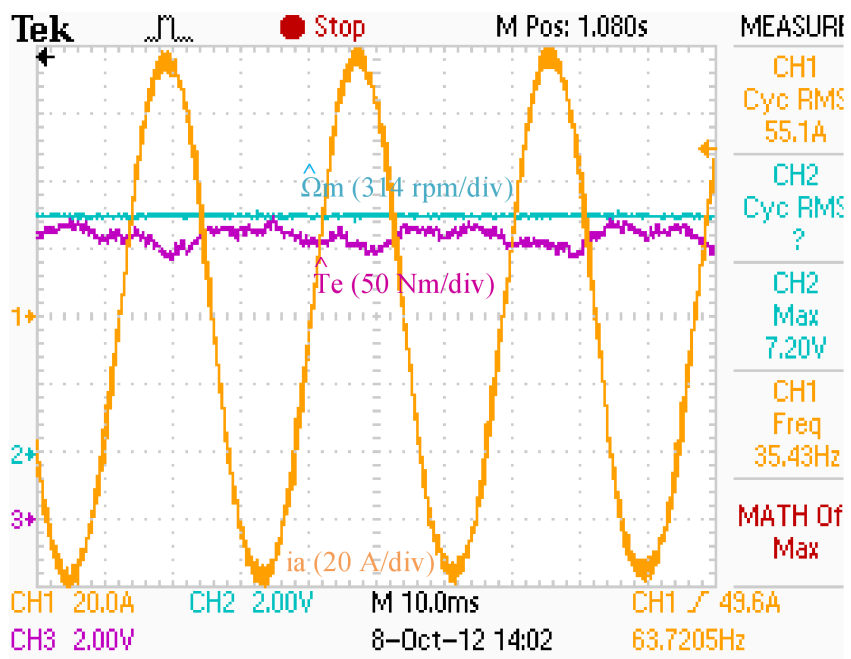

Fig. 8. Steady state operation for $1100 \mathrm{rpm}$ speed and $200 \mathrm{Nm}$ load torque $\left(\widehat{\Omega}_{m}\right.$ - estimated speed, $\widehat{T}_{e}-$ estimated torque, $i_{s a}$ - phase current)

Dynamic performances. Some selected results of dynamic tests are presented in the oscillograms of Figs. 9-12. The excellent torque tracking performance in torque control mode (open speed loop) is shown in Fig. 9. Similarly, in Fig. 10 speed reversal under torque control mode $\pm 150 \mathrm{Nm}$ is shown.

The speed tracking performances are presented in Fig. 11 for speed reference changes: $50 \mathrm{rpm}-900 \mathrm{rpm}-50 \mathrm{rpm}$. As it can be seen the averaged speed error stays within the range of $5 \mathrm{rpm}$ during the transients (acceleration and deacceleration) and around zero for a steady state operation at speed $900 \mathrm{rpm}$.

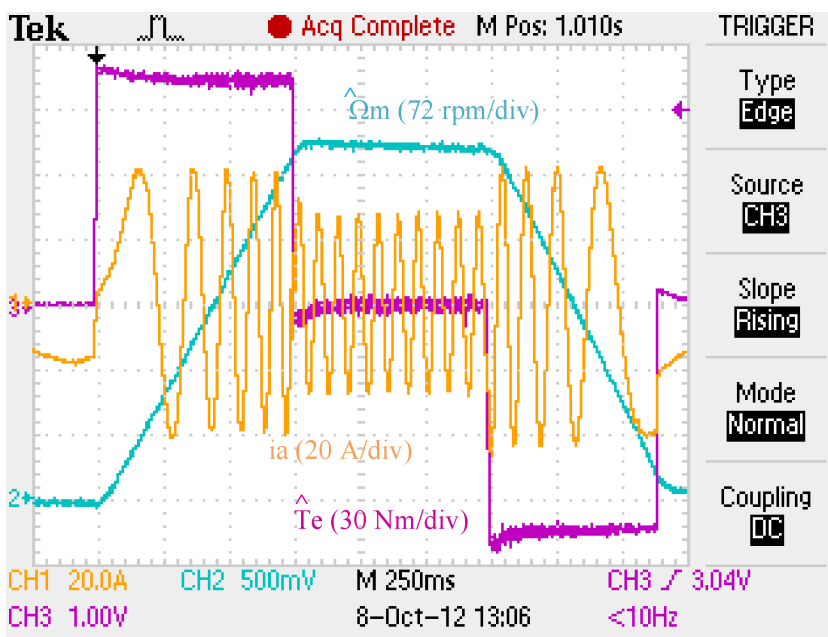

Fig. 9. Operation in torque control mode: torque reference changes $\pm 100 \mathrm{Nm}\left(\widehat{\Omega}_{m}\right.$ - estimated speed, $\widehat{T}_{e}$ - estimated torque, $i_{s a}$ - phase current)

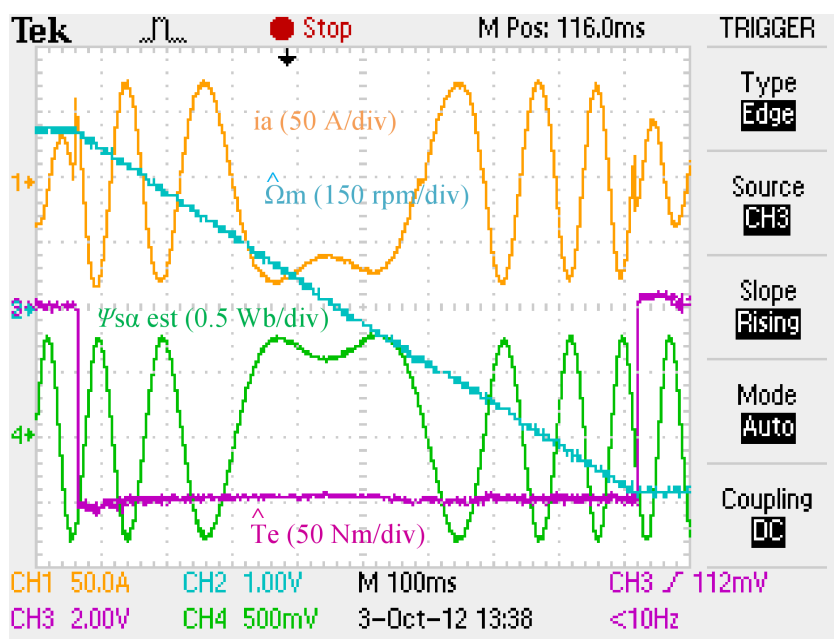

Fig. 10. Speed reversal for torque changes $\pm 150 \mathrm{Nm}\left(\widehat{\Omega}_{m}-\right.$ estimated speed, $\widehat{T}_{e}$ - estimated torque, $i_{s a}$ - phase current, $\widehat{\Psi}_{s \alpha}-$ estimated stator flux)

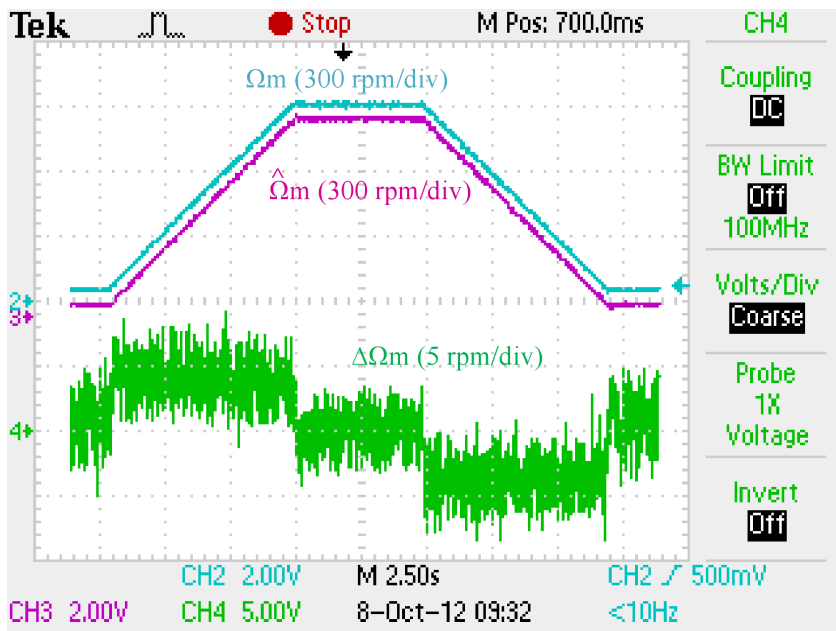

Fig. 11. Speed tracking performance for reference changes 50900-50 rpm $\left(\Omega_{m}\right.$ - speed from a sensor, $\widehat{\Omega}_{m}$ - estimated speed, $\left.\Delta \Omega_{m}=\Omega_{m}-\widehat{\Omega}_{m}\right)$ 
Simple speed sensorless DTC-SVM scheme for induction motor drives

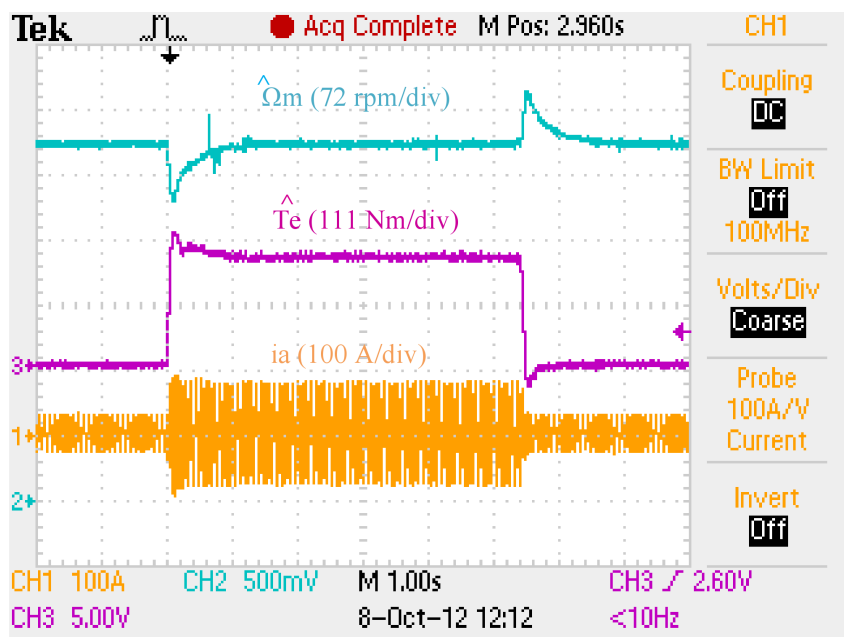

Fig. 12. Response of the speed control loop to step change of the load torque from $0 \mathrm{Nm}$ to $200 \mathrm{Nm}$, for $400 \mathrm{rpm}$ reference speed $\left(\widehat{\Omega}_{m}\right.$ - estimated speed, $\widehat{T}_{e}$ - estimated torque, $i_{s a}$ - phase current $)$

Finally, the performance of the speed stabilization loop under step change of the load torque: $0-200 \mathrm{Nm}-0$ is presented in Fig. 12. Note that electromagnetic torque and stator phase current change very fast without any oscillations.

\section{Conclusions}

In this paper a simple algorithm for fast stator flux and speed estimation is presented and implemented in $50 \mathrm{~kW}$ PWM inverter fed-induction motor (IM) drive. The speed sensorless drive operates in direct torque control with the space vector modulation (DTC-SVM) scheme presented in Fig. 4. The flux vector observer is based on a stator voltage equation and simple algebraic flux-current equations without speed/position signals. In spite of simplicity, the drive can operate in torque or speed control modes, and guarantees a proper dynamic performance and the moderate speed estimation accuracy in steady states.

Acknowledgements. The NPRP grant (NPRP 4-077-2-028) from the Qatar National Research Fund (a member of The Qatar Foundation) made this publication possible. The statements included herein are solely the responsibility of the authors.

\section{REFERENCES}

[1] I. Boldea and S.A. Nasar, Electric Drives, CRC Press, Boca Raton, 2006.

[2] B.K. Bose, "Power electronics and motor drives recent progress and perspective", IEEE Trans. on Ind. Electronics 56 (2), 581-588 (2009).
[3] P. Vas, Sensorless Vector and Direct Torque Control, Clarendon Press, Oxford, 1998.

[4] M. Cirrincione, M. Pucci, and G. Vitale, Power Converters and AC Electrical Drives with Linear Neural Networks, CRC Press, Boca Raton, 2012.

[5] M.P. Kazmierkowski and H. Tunia, Automatic Control of Converter Fed Drives, Elsevier, Amsterdam, 1994.

[6] L. Xu and M. Fu "A sensorless direct torque control technique for permanent magnet synchronous motors", IEEE Industrial Applications Conf. 1, 159-164 (1999).

[7] M.P. Kazmierkowski, L.G. Franquelo, J. Rodriguez, M. Perez, and J.I. Leon, "High-performance motor drives", IEEE Industrial Electronics Magazine 5 (4), 6-26 (2011).

[8] K. Hasse, "Drehzahlgelverfahren fur schnelle Umkehrantriebe mit stromrichtergespeisten Asynchron - Kurzchlusslaufermotoren", Reglungstechnik 20, 60-66 (1972).

[9] F. Blaschke, "The principle of field-orientation as applied to the transvector closed-loop control system for rotating-field machines", Siemens Review 34, 217-220 (1972).

[10] I. Takahashi and T. Noguchi, "A new quick-response and high efficiency control strategy of an induction machine", IEEE Trans. on Industrial Application IA-22 (5), 820-827 (1986).

[11] G.S. Buja and M.P. Kazmierkowski, "Direct torque control of PWM inverter-fed AC motors - a survey", IEEE Trans. on Ind. Electronics 51 (4), 744-757 (2004).

[12] J. Holtz, "Sensorless control of induction machines-with or without signal injection?", IEEE Trans. on Ind. Electron. 53 (1), 7-30 (2006).

[13] D. Casadei, F. Profumo, G. Serra, and A. Tani, "FOC and DTC: two viable schemes for induction motors torque control", IEEE Trans. on Power Electronics 17 (5), 779-787 (2002).

[14] M. P. Kazmierkowski, R. Krishnan, and F. Blaabjerg, Control in Power Electronics, Academic Press, London, 2002.

[15] T. Orłowska-Kowalska, "Application of extended Luenberger observer for flux and rotor time-constant estimation in induction motor drives", IEE Proceedings 136 (6), 324-330 (1989).

[16] R. Nilsen and M.P. Kazmierkowski, "Reduced order observer with parameter adaption for fast rotor flux estimation in induction machines", IEE Proc. D 136 (1), 35-43 (1989).

[17] T. Orłowska-Kowalska and M. Dybkowski, "Performance analysis of the sensorless adaptive sliding-mode neuro-fuzzy control of the induction motor drive with MRAS-type speed estimator", Bull. Pol. Ac.: Tech. 60 (1), 61-70 (2012).

[18] J. Guzinski and H. Abu-Rub, "Speed sensorless induction motor drive with predictive current controller", IEEE Trans. on Industrial Electronics 60 (2), 699-709 (2013).

[19] H. Abu-Rub, and J. Guzinski, "Simple observer for induction motor speed sensorless control", Proc. $37^{\text {th }}$ Annual Conf. IEEE Industrial Electronics Society, IECON 2011 1, 2024 2029 (2011).

[20] dSPACE, RTLib Reference, September 2001.

[21] dSPACE, RTI Reference, September 2001. 